\title{
ON A NEW EXTENSION OF HILBERT'S INEQUALITY
}

\author{
BICHENG YANG AND THEMISTOCLES M. RASSIAS
}

Abstract. This paper deals with a new extension of Hilbert's inequality with a $(p, q)$ - parameter and a best constant factor. We also consider a more extended form and the equivalent inequality.

Mathematics subject classification (2000): 26D15.

Key words and phrases: Hardy-Hilbert's inequality, weight coefficient, $\beta$ function, Hölder's inequality.

\section{REFERENCES}

[1] G. H. Hardy, J. E. LitTlewood and G. Polya, Inequalities, Cambridge University Press, Cambridge, 1952.

[2] BICHENG YANG, On a generalization of Hilbert's double series theorem, Math. Inequal. and Appl., 5, 2 (2002), 197-204.

[3] Mingzhe GaO, Shongrong Wei And Leping He, On the Hilbert inequality with weights, Journal for Analysis and its Applications, 21, 1 (2002), 257-263.

[4] BiCHENG YANG, L. DEBNATH, On a new generalization of Hardy-Hilbert's inequality and its applications, J. Math. Anal. Appl., 233, (1999), 484-497.

[5] D. S. Mitrinović, J. E. PeČARIĆ AND A. M. FinK, Inequalities Involving Functions and Their Integrals and Derivertives, Kluwer Academic Publishers, Boston, 1991.

[6] BICHENG YANG, On a strengthened version of the more accurate Hardy-Hilbert's inequality, Acta Mathematica Sinica, 42, 6 (1999), 1103-1110.

[7] Bicheng YANG, On a strengthened Hardy-Hilbert's inequality, J. Ineq. Pure Appl. Math., 1, 2 (2000), Article 22.

[8] Bicheng YANG, T. M. RASSIAS, On the way of weight coefficient and research for the Hilbert-type inequalities, Math. Inequal. Appl., 6, 4 (2003), 625-658.

[9] ZhuXi Wang, Dunren Guo, An Introduction to Special Functions, Science Press, Beijing, 1979.

[10] Jichang KuAng, L. DeBnath, On new generalizations of Hilbert's inequality and their applications, J. Math. Anal. Appl., 245, (2000), 248-265. 